\title{
XVI. Diurnal periodicity of the spontaneous ionization of air and other gases in closed vessels
}

\author{
Alexander Wood B.A. D.Sc.(Glas.) \& Norman R. Campbell M.A.
}

To cite this article: Alexander Wood B.A. D.Sc.(Glas.) \& Norman R. Campbell M.A. (1907) XVI. Diurnal periodicity of the spontaneous ionization of air and other gases in closed vessels, Philosophical Magazine Series 6, 13:74, 265-276, DOI: 10.1080/14786440709463599

To link to this article: http://dx.doi.org/10.1080/14786440709463599

曲 Published online: 16 Apr 2009.

Submit your article to this journal $₫$

Џll Article views: 3

Q View related articles $\square$

Citing articles: 4 View citing articles 5 
Spontaneous Ionization of Air and other Gases.

while those of electric force are given by

$$
\begin{aligned}
& \frac{\iota k x}{\mathrm{~V}}=n \cdot n+1 . \mathrm{D}_{n}^{m} r^{-\frac{3}{2}} \mathrm{~J} . \mathrm{P}_{n}^{m}(\mu) \cos \left(m \omega+\delta_{n}^{m}\right) \\
& \frac{\iota k y}{\mathrm{~V}}=-m \mathrm{C}_{n}^{m} \boldsymbol{r}^{-\frac{2}{2}} \mathbf{J} \cdot \frac{\mathrm{P}_{n}^{m}}{\sin \theta} \cdot \sin \left(m \omega+\epsilon_{n}^{m}\right) \\
& -\mathrm{D}_{n}^{m} r^{-1} \frac{d}{d r^{2}}\left(r^{\frac{1}{2} \mathrm{~J}}\right) \sin \theta \frac{d \mathrm{P}_{n}^{m}}{d \mu} \cos \left(m \omega+\delta_{n}^{n 2}\right) \\
& \frac{\iota k z}{\mathrm{~V}}=\mathrm{C}_{n}^{m} r-\mathrm{s} \mathrm{J} \cdot \sin \theta^{\frac{d \mathrm{P}_{n}}{d \mu}}-\cos \left(m \omega+\epsilon_{n}^{m}\right) \\
& -m \mathrm{D}_{n}^{m} r^{-1} \frac{d}{d r}(r \mathrm{~J}) \cdot \frac{\mathrm{P}_{n}^{m}}{\sin \theta} \sin \left(m \omega+\delta_{n}^{m}\right), . \quad \text {. }
\end{aligned}
$$

where J may now be taken as $\underset{n+\frac{1}{2}}{J}(k r)+\lambda_{n} \mathrm{~J}(k r)$.

When, in $(x, y, z)$; or $(a, b, c)$, we add to $\mathrm{P}_{n}^{m}$ an arbitrary multiple of the associated harmonic of type $Q_{n}^{m}$, and perform a summation for all integral values of $m$ and $n$, we obtain the most general solution of the circuital relations corresponding to wave motion. In this form, the results are more appropriate to electromagnetic problems involving spheres, than those ordinarily given, their main utility lying in the fact that they give the radial and transversal components directly. For example, the period equations of free vibration of the space between two conducting spheres may be written down at once, and are seen to be independent of the question as to whether the vibrations are symmetrical* or tesseral.

XVI. Diurnal Periodicity of the Spontaneous Ionization of Air and other Gases in Closed Vessels. By Alexander Wood, B.A., D.Sc. (Glas.), Lecturer, Emmanuel College, Cambridge; and Norman R. CaMpbali, M.A., Fellow of Irinity College, Cambridge†.

IF a stream of air be drawn through a metal vessel which 1 is subsequently sealed up, the spontaneous ionization in the vessel undergoes a progressive change which has been investigated by several observers. Since the conclusions reached were various and sometimes conflicting, a new and careful series of experiments was undertaken. It was soon found that the phenomenon was more complicated than had

* Phil. Mag. May 1906; Macdonald, ' Electric Waves,' chap. 3.

† Cummunicated by Prof. J. J. Thomson. 
at first been supposed; for, imposed upon the progressive change of the ionization, which may continue for some weeks, there is a periodic diurnal variation of the ionization. It was considered advisable to investigate this latter change more completely, abandoning for the present the original purpose of the research.

The existence of such diurnal variations has been suspected by several observers. Both of the authors*, when conducting separate experiments on spontaneous ionization, have been troubled by inexplicable variations in the current through their vessels; the current seemed smallest in the afternoon. Jaffé $\dagger$ also noticed the variations, and investigated them in some detail, concluding that there was a minimum at 2 P.M. Borgmann $\ddagger$ states that the minimum of ionization is at 3 P.M. The first three observers had all worked at Cimbridge, but since their experiences agree with those of Borgmann, it is probable that the effects are not due to local causes. A similar diurnal periodicity of the amount of radioactive emanation in the atmosphere has been observed by Dike $\$$. His curve is obtained from the observations on six days only, so that it is impossible to attach much importance to its details, but its principal maximum (1 A.M.) agrees fairly well with one of the maxima of the ionization in our vessels.

As it was desired to vary the gas in which the ionization was to be measured as well as the metal of which the vessel was made, the first difficulty to be solved was the construction of a vessel which would hold hydrogen or coal-gas for several weeks. In the end the following device was adopted. The vessel, which had a capacity of about 6000 ces., was placed on a brass plate and covered with a glass bell-jar. The belljar was cemented down to the plate with marine glue, and could then be exhausted and filled with any required gas. As the experimental vessel was thus placed in an atmosphere of the gas, no precautions were necessary to have it absolutely gas-tight. An insulated electrode passed throngh the brass plate up into the vessel, and the vessel was kept charged to a constant high potential in the usual way. The arrangement was found to hold a good vacuum for a considerable time. In order to obtain continuous readings of the ionization in the vessel, a device employed by Bronson \| was used. The

* N. R. Campbell, Phil. Mag. April 1905, p. 534; A. Wood, ibid. p. 562.

$\dagger$ G. Jaffe, Phil. Mag. Oct. 1904, p. 556.

† J. J. Borgmann, see 'Science A bstracts,' 1904, No. 1580.

\$ 'Terrestrial Magnetism,' vol. xi. No. 3, p. 128.

il H. Bronson, Phil. Mag. Jan. 1906, p. 143. See also C. Nordman, Comptes Rendus, cxxxviii. pp. 1418-1420 \& 1596-1599. 
Periodicity of the Spontaneous lonizution of Air, etc. 267

electrode was connected to one pair of quadrants of a quadrant electrometer, and also to earth through a vessel, containing air ionized by uranium, which acted as a high resistance. The other pair of quadrants of the electrometer were connected to earth, and in this way the readings of the electrometer were, for small variations, directly proportional to the ionization. During the day the spot of light from the mirror was read on a scale in the ordinary way-the value of the scale readings being found by comparison with a potentiometer. At night the spot was projected on to a cluck-driven drum covered with bromide-paper, and the initial and final readings of the potential being known from the scale readings, the intermediate values could bo found by measurement of the trace.

It was thus possible to experiment with any gas in a vessel of any metal, and at first a great many combinations were tried. A zinc vessel was filled successively with hydrogen, coal-gas, carbon dioxide, and air; a lead vessel with carbon dioxide, coal gas, and air ; and a tin vessel with air. As the apparatus took some time to adjust itself, it was found to be impossible to study the initial changes in the ionization, but a record of the subsequent changes extending over several days, and in some cases over several weeks, was obtained. Curves have been drawn to represent these changes, and it will be seen that they exhibit two main features. In most cases there is a gradual increase of the jonization with the time. This had been previously observed by Burton and McLennan * but whereas they found the increase to be rapid at first, then to fall away, and finally to cease altogether, leaving the ionization at a steady value, we found a fairly steady increase, which was maintained over a period of ten days or more. It is just possible that this difference is to be explained in some way by the differences in size of the vessels used.

This increase occurred in the case of lead with each of the gases tried, and so would seem to be characteristic of the motal rather than of the gas. The curves representing the change of ionization with time are shown for lead and carbon dioxide in fig. 1, and for lead and coal-gas in fig. 2. The abscissæ are hours of the day, and the ordinates are the corresponding values of the ionization. Each separate curve represents one day. It will be seen that the curves lie successively above one another and that they differ by approximately equal intervals. In the case of zinc, however, no such increase has been found except in the single case

* Physs. Review, iv. 1903. 
when the vessel contained coal-gas. Coal-gas is so uncertain in composition that little importance is attached to this result. Air was enclosed in the zinc vessel on the 10th of August this year, and its ionization measured on our scale was found to be 0.513 . It was left enclosed until the 12 th of October, and the ionization was then 0.521. The behaviour of the tin was similar to that of the lead, and showed a gradual increase in the ionization extending over the whole period of the investigation.

By far the most interesting feature of the curves, however, is their periodic character. This is quite well marked in the curves for lead, indeed it was in the curves for lead and carbon dioxide that it was first noticed. It will be seen that

Fig. 1.

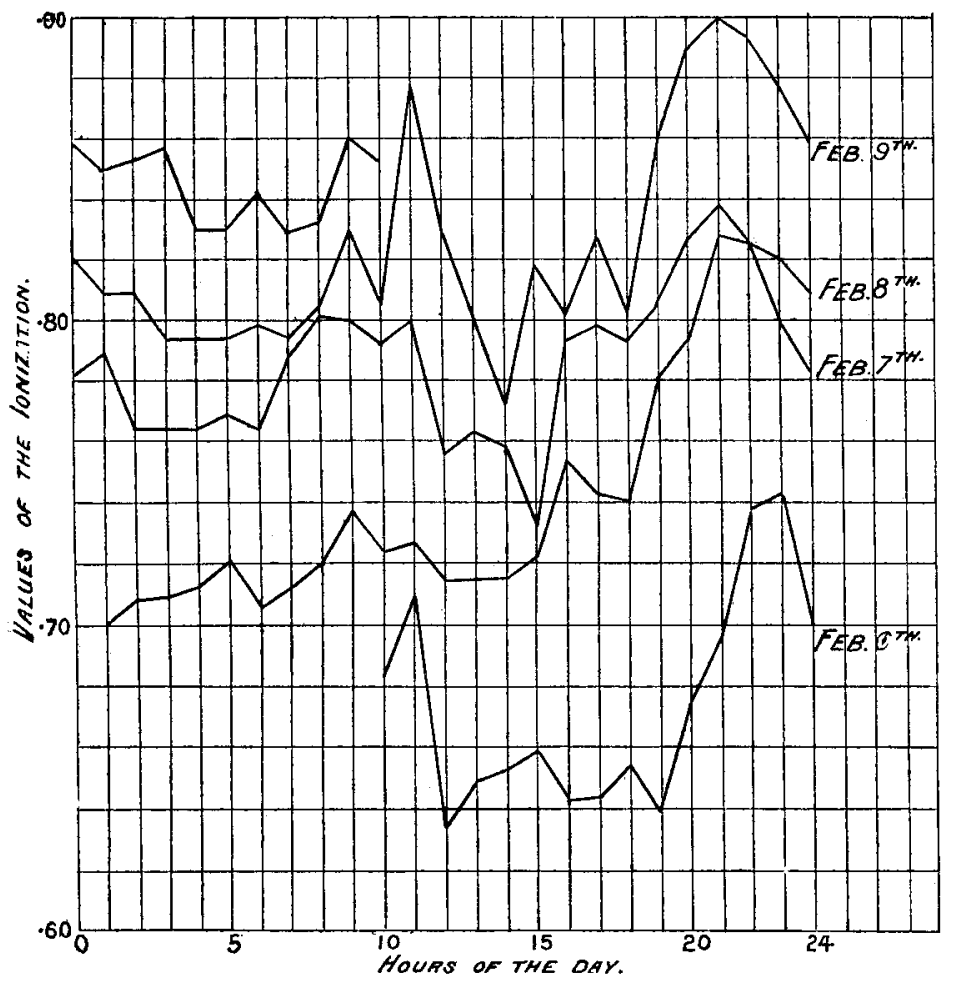

Lead and Carbon Dioxide.

in fig. 1 each curve shows a very marked maximum at a time varying from 21 hours (9 P.M.) to 23 hours (11 P.M.) and a 
Periodicity of the Spontaneous Ionization of Air, etc. 269 minimum between $12 \mathrm{~h}$. and $15 \mathrm{~h}$. Not quite so well defined but still quite obvious are the second maximum occurring between $8 \mathrm{~h}$. and $11 \mathrm{~h}$, and the second minimum occurring between $2 \mathrm{~h}$. and $6 \mathrm{~h}$. The curves for lead and carbon dioxide thus show a double daily period. Looking now at the curves for lead and coal-gas (fig.2), we find that

Fig. 2.

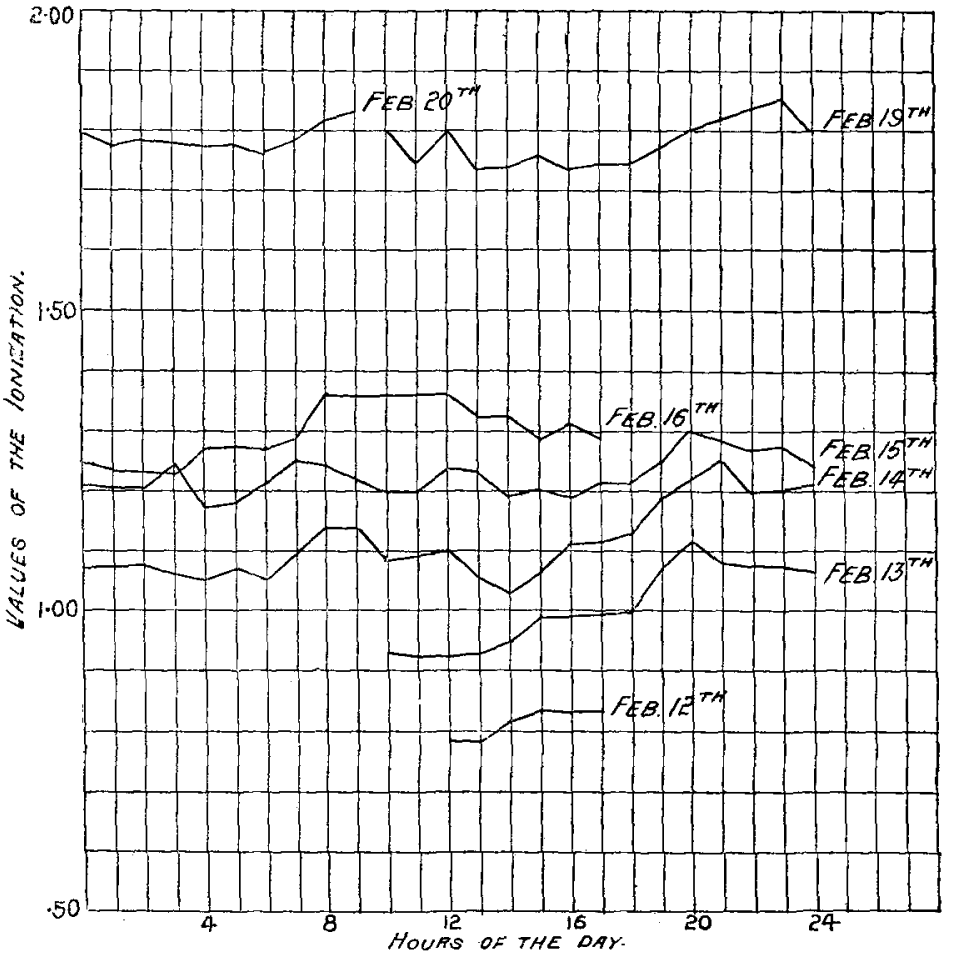

Lead and Coal-Gas.

the scale to which they are drawn makes them appear more regular, but the same features are apparent. Once more each curve shows a well marked maximum between $20 \mathrm{~h}$, and $23 \mathrm{~h}$., and a minimum between $12 \mathrm{~h}$. and $16 \mathrm{~h}$. Another maximum may be observed between $7 \mathrm{~h}$. and $10 \mathrm{~h}$, and a second minimum between $3 \mathrm{~h}$. and $6 \mathrm{~h}$. From this and other similar evidence it is concluded that the periodic variation of the ionization in the vessel is independent of the nature of the gas enclosed.

Phil. Mag. S. 6. Vol. 13. No. 74. Fel. 1907. 
The next point of importance was to determine whether the periodicity was peculiar to lead ressels. Fig. 3 shows a set of curves drawn for zine and earbon dioxide similar to those already given for lead. Here again the periodicity is quite evident, and the above noted maxima and minima can

Fig. 3.

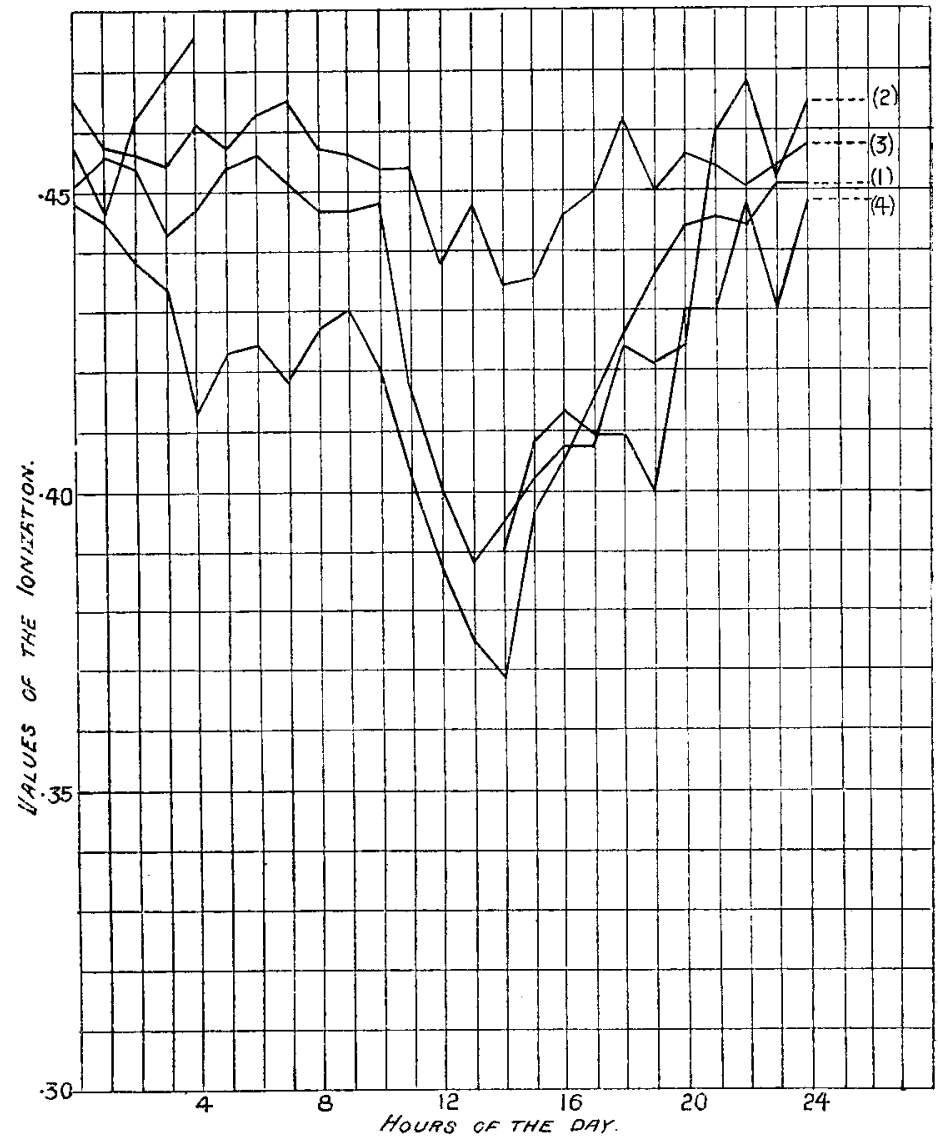

Curves for Zinc and Carbon Dioxide. March 5-8.

all be recognized. One very marked difference in this diagram is the frequent intersection of the curves representing successive days. This is due to the fact that little or no permanent increase in the ionization occurred. Sevoral other similar sets were obtained for zinc, the gases used including coal-gas, air, and hydrogen. All the sets showed the same 
Periodicity of the Spontaneous Ionization of Air, ets. 271 periodic variation; and hence we are forced to conclude that this periodicity is independent not only of the gas enclosed in the vessel but also of the metal of which the vessel is made. Mean curves for the three different sets of curves already given were drawn and are represented in fig. 4 .

Fig. 4.

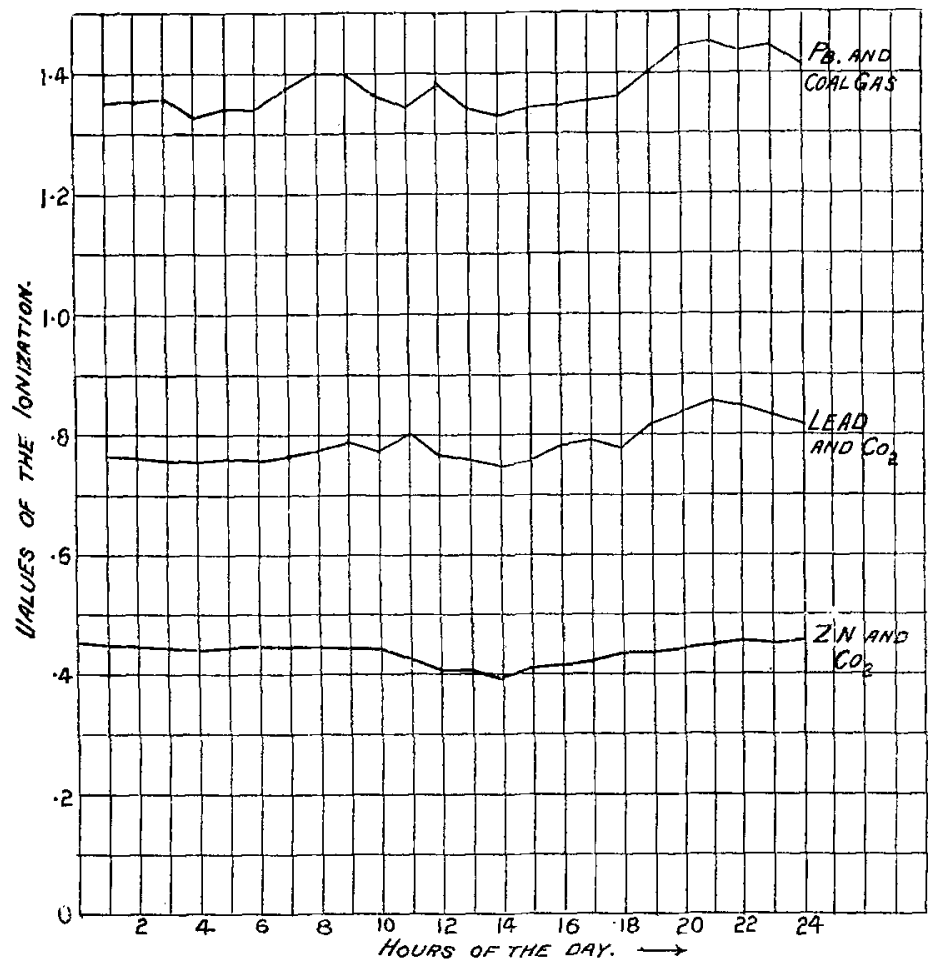

This brings out the similarity still more clearly, and is sufficient justification for drawing a single mean curve to represent the three sets of results. This is shown in fig. 5 (p. 272).

For subsequent results it will be more convenient to draw our curves in a somewhat different way. It was assumed that the permanent increase of ionization which took place from day to day with lead and with zinc (when coal-gas was enclosed) was uniform throughout each day. Its value was found by comparing the mean values of the ionization on each of two consecutive days. The corresponding day's 
values of the ionization were then corrected for the rise, and the excess or defect of the value of the ionization for each hour of the day from the mean value for the day was plotted. In this way all the later curves were obtained.

Fig. 5.

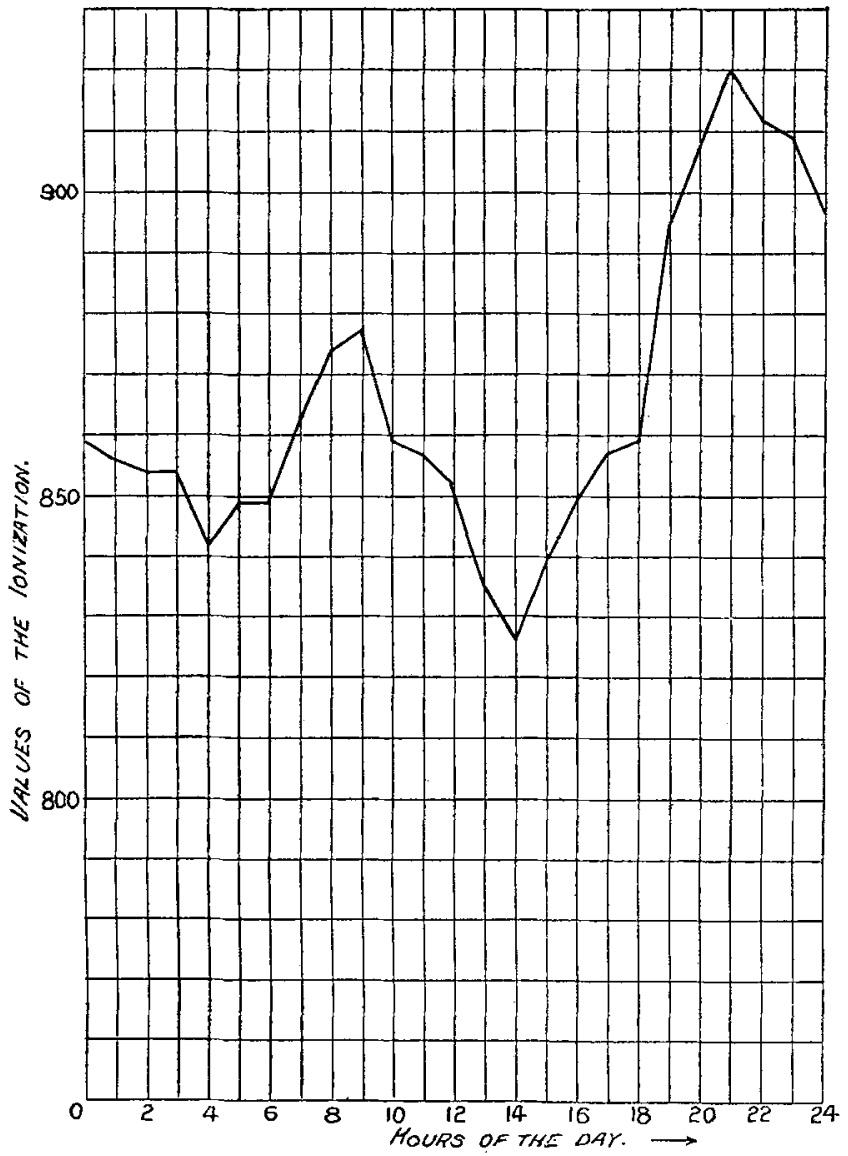

Mean of Curves in Fig. 4.

The periodic character of the variation was at first attributed to temperature as the mosc probable cause, and one of Callendar's patent recording thermometers, kindly put at our disposal by the Cambridge Scientific Instrument Company, was installed alongside of the apparatus. It was found 
Periodicity of the Spontaneous Ionization of Air, etc. 273

to be impossible to connect the temperature curve with the ionization curve in any way. The temperature curve had only one maximum and one minimum, so that if there be any connexion between the two curves the periodicity of the ionization must depend on some differential coefficient of the temperature. Then, again, the nature of the temperature curve depended entirely on the hot-water pipes, and was quite different on Saturdays and Sundays from the rest of the week, whereas we were unable to detect any change whatever in the character of our curves on these days.

The next quantity, variations of which were measured with a view to connecting them with the variations of the ionization, was atmospheric potential. It was at once evident that there was a close similarity between the curves representing the simultaneous variation of the two quantities. For some time, the atmospheric potential recorder at the Observatory here was run with the kind assistance of Mr. A. R. Hinks, but in the end it was found to be unnecessary, as the very full data published of the observations at Kew, when used instead, brought out the same similarity and at the same time showed that it conld not be due to local canses.

In figs. 6 to 10 the ionization curves and the atmospheric

Fig. 6.

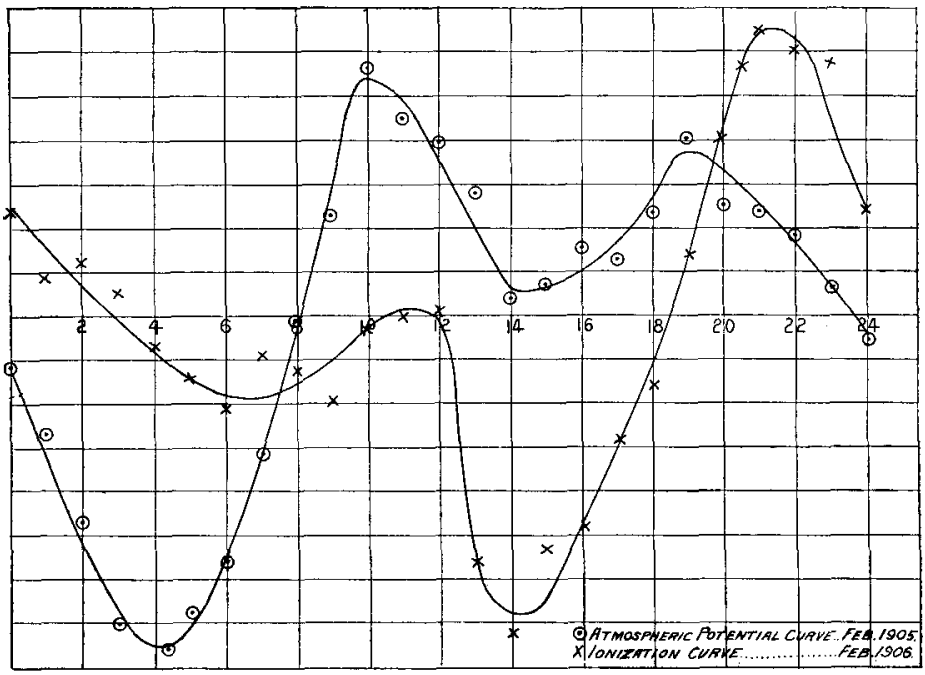

potential curves for the same month are plotted together. There is no connexion between the scales representing the 
values of the two quantities. They are so chosen as to give nearly the same range in the two cases.

Fig. 7 .

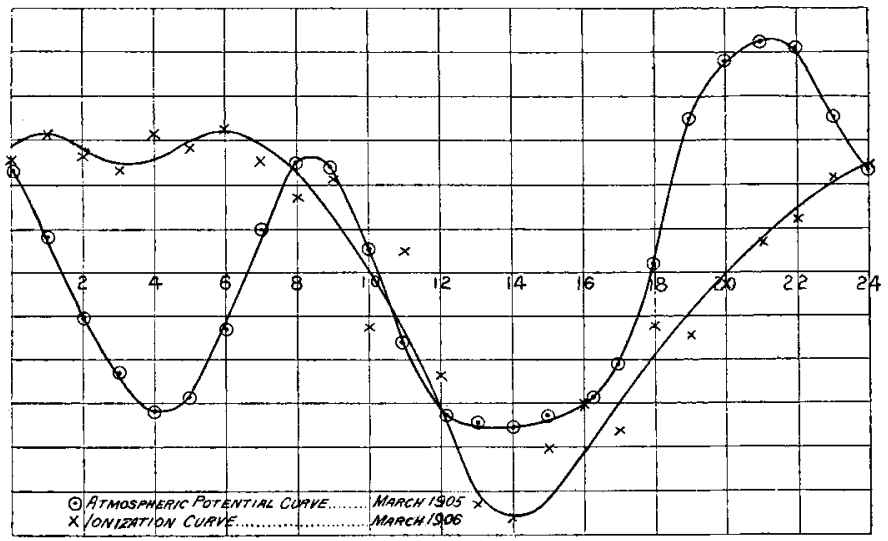

Fig. 8.

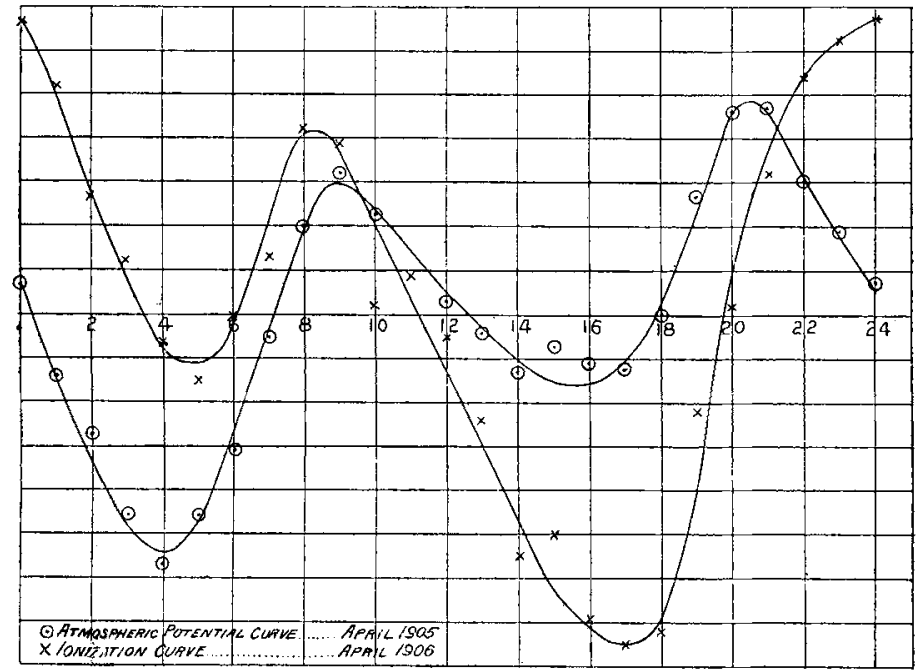

Lead was found to give a somewhat greater mean daily range than zinc, but the smaller total ionization of the zinc made the proportional range greater for ziiic than for lead. In nine successive days in August the value of this ratio was $0 \cdot 12,0 \cdot 09,0 \cdot 17,0 \cdot 14,0 \cdot 18,0 \cdot 16,0 \cdot 12,0 \cdot 14,0 \cdot 09$; this gives a mean of 0.12 , so that the variation in the ionization in the course of one day amounts to about 12 per cent. of 
Periodicity of the Spontaneous Ionization of Air, etc. 27.5

the whole. On comparing corresponding curves in figs. 6 to 10 , it will be seen that the general forms of the curves are the same and that the maxima and minima correspond very closely. In order to make it quite clear that this does not

Fig. 9.

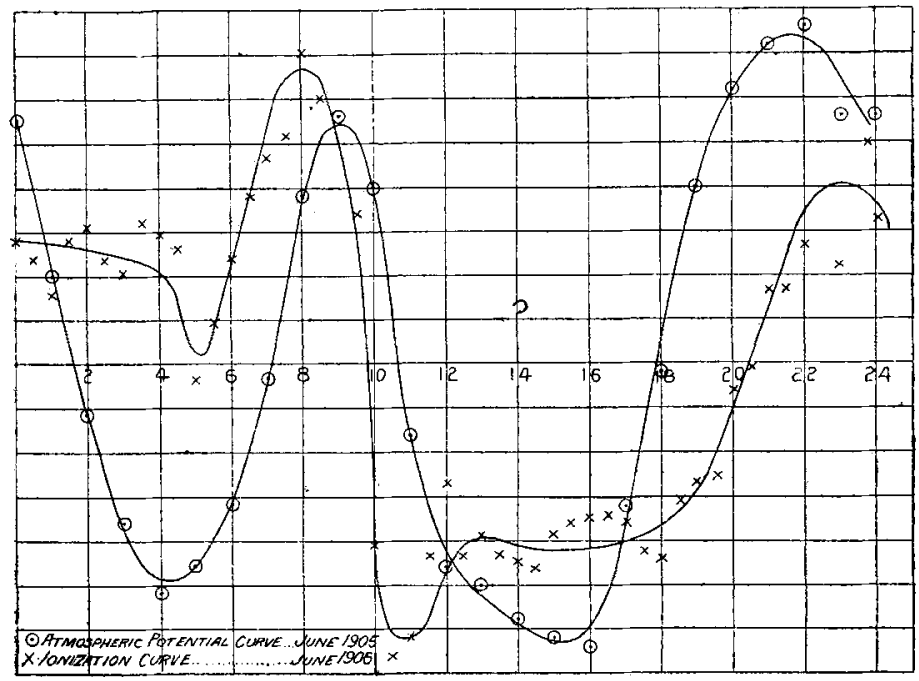

Fig. 10.

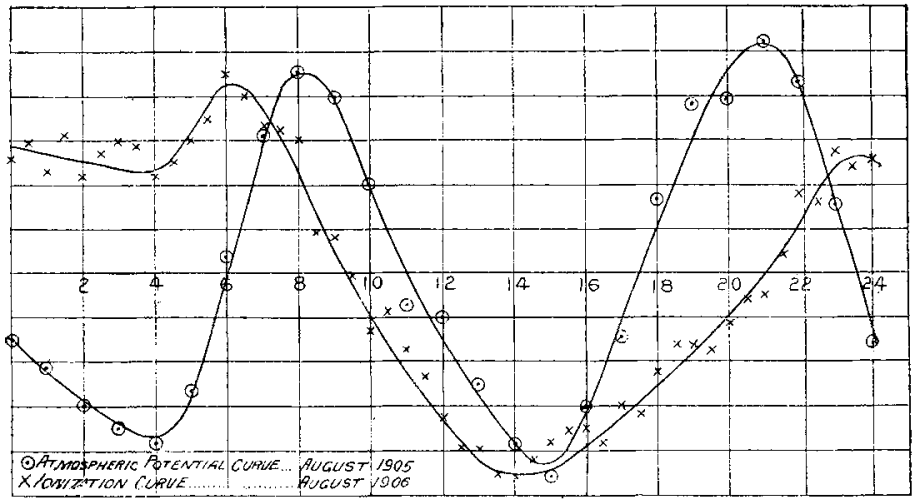

depend on the drawing of the curves, a table is given of the times at which actual maxima and minima points were observed. The times at which corresponding maxima and minima occurred are placed alongside one another in the same vertical column, the times for the atmospheric potential curves being always placed first. 
Spontaneous Ionization of Air and other Gases.

\begin{tabular}{|c|c|c|c|c|}
\hline Month. & 1st Min. & Ist Max. & 2nd Min. & 2nd Max. \\
\hline Feb. & $4 \mathrm{~h} . \quad 6 \mathrm{~h}$. & $10 \mathrm{~h} .12 \mathrm{~h}$. & 14 h. 14 h. & 19 h. $21 \mathrm{~h}$. \\
\hline March ....... & $4 \mathrm{~h} . \quad 3 \mathrm{~h}$. & $8 \mathrm{~h} . \quad 6 \mathrm{~h}$. & $14 \mathrm{~h} .1 \pm \mathrm{h}$. & $21 \mathrm{~h} . \quad 1 \mathrm{~h}$. \\
\hline April ................. & $4 \mathrm{~h} . \quad 5 \mathrm{~h}$. & $9 \mathrm{~h} . \quad 8 \mathrm{~h}$. & $14 \mathrm{~h} .17 \mathrm{~h}$. & $21 \mathrm{~h}, 24 \mathrm{~h}$. \\
\hline June $\ldots \ldots$ & $4 \mathrm{~h} .5 \mathrm{~h}$. & 9 h. 8 h. & $16 \mathrm{~h} .10 \frac{1}{2} \mathrm{~h}$. & 22 b. $22 \frac{1}{3}$ b. \\
\hline August ....... & 4 b. $\quad 4$ b. & $8 \mathrm{~h} .6 \mathrm{~h}$. & $15 \mathrm{~h} .14 \mathrm{~h}$. & $21 \mathrm{h.} 23 \mathrm{~h}$. \\
\hline Means. & $4 \mathrm{~h} . \quad 4 \frac{1}{2} \mathrm{~h}$. & 9 h. $8 \mathrm{~h}$. & $14 \mathrm{~h} .14 \mathrm{~h}$. & $21 \mathrm{~h}, 23 \mathrm{~h}$. \\
\hline
\end{tabular}

The close agreement of all these figures, and especially of the means, seems to be sufficient to establish a connexion between the two quantities involved. It may be noted that the atmospheric potential curves represent observations in fine weather only, while our observations were taken quite irrespective of weather conditions. So far as we could tell the weather conditions were entirely without effect on the ionization.

An attempt was made to analyse these curves into Fourier series without success. The curves were smoothed out and account was taken of the first four components, but no constant results were obtained. The apparatus has recently bren improved, and in future months it is hoped that observations may be taken more continuously. In this way smoother curves may be obtained, and these may possibly analyse.

Briefly, then, the paper seeks to establish the following points :-

(1) The ionization in a closed vessel undergoes a permanent increase for a considerable time after the gas contained in it has been enclosed, but this increase depends on the nature of the vessel, being comparatively large for lead and tin vessels and negligible for zine vessels.

(2) Superimposed on this variation of the ionization is a periodic variation having two maxima and two minima each twenty-four hours.

(3) In their main features the curves representing this periodic change are the same as the curves representing the variations of atmospheric potential, and it is hoped in a later paper to establish a connexion between the two variations. For a possible connexion the reader may be referred to Richardson's letter to 'Nature" .

The authors welcome another opportunity for expressing their indebtedness to Professor Thomson.

* 'Nature,' April 26, 1906, p. 607. 